\title{
CORRIGENDUM
}

\section{Healthy behavior and memory self-reports in young, middle-aged, and older adults}

\author{
Gary W. Small, Prabha Siddarth, Linda M. Ercoli, ${ }^{1}$ Stephen T. Chen, David A. Merrill ${ }^{1}$ \\ and Fernando Torres-Gil
}

Published online by Cambridge University Press, 21 February 2013

doi: $10.1017 / \mathrm{S} 1041610213000082$

The authors regret the following information was omitted from the manuscript in error.

The University of California, Los Angeles, owns a US patent (6274119) entitled "Methods for Labeling $\beta$-Amyloid Plaques and Neurofibrillary Tangles." Dr. Small is among the inventors, has received royalties, and may receive royalties on future sales. Dr. Small reports having served as an advisor for and/or having received lecture fees from Pfizer, Janssen, Herbalife, Novartis, and Lilly. Dr. Small also reports having received a grant funds from POM Wonderful. Drs. Siddarth, Ercoli, Chen, Merrill, and Torres-Gil have no financial conflicts of interest.

\section{Reference}

Small, G. et al. (2013). Healthy behavior and memory self-reports in young, middle-aged, and older adults. International Psychogeriatrics. doi: 10.1017/S1041610213000082. 